\title{
BMJ Open Quality Demand and capacity in an ADHD team: reducing the wait times for an ADHD assessment to 12 weeks
}

\author{
Laura Ann Roughan, ${ }^{1}$ Jamie Stafford ${ }^{2}$
}

To cite: Roughan LA, Stafford J. Demand and capacity in an ADHD team: reducing the wait times for an ADHD assessment to 12 weeks. BMJ Open Quality 2019;8:e00653. doi:10.1136/ bmjoq-2019-000653

- Additional material is published online only. To view, please visit the journal online (http://dx.doi.org/10.1136/ bmjoq-2019-000653).

Received 7 February 2019 Revised 27 August 2019 Accepted 10 September 2019

Check for updates

(c) Author(s) (or their employer(s)) 2019. Re-use permitted under CC BY-NC. No commercial re-use. See rights and permissions. Published by BMJ.

${ }^{1}$ City and Hackney CAMHS, East London NHS Foundation Trust, London, UK

${ }^{2}$ Quality Improvement, East London NHS Foundation Trust, London, UK

Correspondence to Dr Laura Ann Roughan; I.roughan@nhs.net

\section{ABSTRACT}

Attention deficit hyperactivity disorder (ADHD) is a behavioural disorder characterised by the core symptoms of hyperactivity, impulsivity and inattention. ADHD is thought to affect about 3\%-9\% of school-age children and young people in the UK. With increased awareness and early identification of ADHD, and the long-term impact of the condition, there is a growing demand for ADHD services for both assessment and treatment of children and young people with the condition. Demand and capacity modelling carried out in 0ctober 2017 identified the ADHD pathway team in City and Hackney Child and Adolescent Mental Health Service (CAMHS) were working at $127 \%$ utilisation, indicating a mismatch between capacity and demand. A quality improvement (QI) project was implemented to improve efficiency and effectiveness of processes within the team and to support the increasing demand within the limited capacity and resource. The aim of the project was to reduce the average length of time from initial referral to CAMHS to 'ADHD assessment feedback' to 12 weeks by September 2018, which is in line with trust-level targets. The team followed the model for improvement and guidance from East London Foundation Trust (ELFT) QI Microsite to structure the project. They used a variety of tools to develop a theory of change, and used Plan-Do-Study-Act cycles to test change ideas. Overall wait times have reduced from 28 weeks to below our target of 12 weeks. Data examining the entry point to the ADHD pathway to completion of the ADHD assessment and feedback reduced from an average of 87 days, to an average of 18 days. The diagnostic rate has increased from $62 \%$ to $78 \%$ (due to more appropriate screening and referrals). The QI approach was systematic and supported the development of more efficient systems; reducing wait times and increasing capacity to manage the demand. Team engagement in 'change', by embedding Ql into fortnightly team meetings, has resulted in collective ownership and responsibility across team members. A monitoring system is supporting the sustainability and maintenance of improvement.

\section{PROBLEM}

In recent years, the government have started to prioritise children and young people's mental health. For example, the National Health Service (NHS) transformation plans for children and young people's mental health provision ${ }^{1}$ focus on early identification, increasing access to services and reducing waiting times for children and young people and more recently the Government's Green Paper on Transforming Children and Young People's Mental Health Provision ${ }^{2}$ bring about change and increased funding for CAMHS. All data relevant to the study are included in the article.

The Children's Commissioner Report ${ }^{3}$ recently highlighted the disparity in waiting times in CAMHS. To date, guidance on the assessment and treatment of attention deficit hyperactivity disorder (ADHD) focuses on the information clinicians should gather to determine whether an ADHD diagnosis can be made (eg, National Institute for Health and Care Excellence (NICE) guidelines). ${ }^{4}$ Services in other parts of the country have produced good practice guidance for assessment and treatment of ADHD, ${ }^{5}$ but these also do not stipulate waiting times. While quality improvement (QI) methodology has been used to reduce waiting times before, ${ }^{6}$ there were no published studies looking to reduce waiting times in CAMHS ADHD assessments to date.

In City and Hackney, we serve a population of 273526 people with $25 \%$ of the population being under 18 years of age. ${ }^{7}$ It is a growing population with an estimated $15 \%$ increase in population since 2011 and projection figures set to continue to rise. City and Hackney is a culturally diverse borough of London with large communities of Turkish/Kurdish residents and the Charedi Jewish community concentrated in the North East of the borough. Hackney has a higher than national average percentage of children in low-income families and it has historically been one of the most deprived areas in the country, although this has begun to change in recent years. One in 10 children aged 5-16 years have a diagnosable mental health disorder, ${ }^{1}$ with ADHD being the most prevalent childhood psychiatrist diagnosis. ${ }^{8}$ Children from low income families are at highest risk. 
Estimates on current prevalence in City and Hackney suggest an under-representation of those with ADHD symptoms accessing services. However, with increased awareness and early identification of ADHD, and the longterm impact of the condition, there is a growing demand for ADHD services for both assessment and treatment of children and young people with the condition.

City and Hackney CAMHS has streamlined its treatment pathways in recent years, which means that those children and young people with suspected ADHD come straight to a multidisciplinary neurodevelopmental pathway. The neurodevelopmental pathway attempts to further divide cases into has two streams, those requiring an ADHD assessment and those who are being referred for an autism spectrum disorder (ASD). The focus of the paper is on the ADHD pathway, although we appreciate there is often overlap in assessments. In the ADHD assessment pathway, we are able to access further assessment for ASD and/or learning needs from the wider neurodevelopmental pathway in order to gain a full understanding of the child. Where further assessment was necessary, this is completed as part of the assessment process. While streamlining cases into pathways, means children and young people with ADHD are identified earlier, the small team ( 0.5 wte psychiatrist, 1.5 wte nursing and the equivalent of 1 wte clinical psychologist) were managing a high proportion of the referrals into CAMHS. This meant the service was presented with demand and capacity issues.

New referrals into CAMHS go through an initial assessment clinic where families are seen by a senior clinician in order to get an understanding of the presenting problem, signpost where more appropriate and to decide on an initial care plan in CAMHS. Following on from this, the ADHD pathway were receiving an average of nine new referrals per month for children and young people referred for an ADHD assessment. The job of clinicians in the pathway was then to get standardised measures such as the Conners forms ${ }^{9}$ from parents and teachers, complete relevant observations (eg, in clinic/school) and complete an interview with parents/carers taking into account developmental and psychosocial factors as well as screen for other co-existing or differential mental health diagnosis and feedback to families and where appropriate the child/young person's school.

At the time of the initiation of the QI project, this process was taking up to 28 weeks from referral to CAMHS to completion of the ADHD assessment. Variation between cases was high and treatment offers following assessment were sporadic.

We modelled demand and capacity in our system as per the demand and capacity programme, NHS England. ${ }^{10}$ This modelling carried out in October 2017 identified the ADHD team were working at $127 \%$ utilisation, indicating a mismatch between capacity and demand. City and Hackney CAMHS have undertaken a QI project to improve efficiency and effectiveness of processes within the team and to support the increasing demand within the limited capacity and resource.
The QI project aimed to reduce the average length of time from initial referral to CAMHS to 'ADHD assessment feedback' to 12 weeks by September 2018, which is in line with our trust targets.

\section{BACKGROUND}

ADHD is one of the syndromes defined in the Diagnostic and Statistical Manual of Mental Disorders (DSM). ${ }^{11} 12$ In the DSM- $5,{ }^{12}$ it is described as a neurodevelopmental disorder with a persistent behavioural pattern of severe inattention and/or hyperactivity/impulsivity. The behaviours must be uncharacteristic for the developmental age of the child, be manifest in different settings (eg, at home and at school), have started before the age of 12, be present for at least 6 months and interfere with social and academic performance.

Based on the narrower criteria of the International Statistical Classification of Diseases and Related Health Problems, 10th Revision (ICD-10),${ }^{13}$ hyperkinetic disorder is estimated to occur in about $1 \%-2 \%$ of children and young people in the UK. Using the broader criteria of DSM-IV, ${ }^{11}$ ADHD is thought to affect about 3\%-9\% of school-age children and young people in the UK. Recent follow-up studies of children with ADHD show that the condition persists from childhood to adolescence in $50 \%-80 \%$ of cases and into adulthood in $35 \%-65 \%$ of cases. ${ }^{14}$ In a 16-year follow-up study, psychosocial, educational and neuropsychological functional impairments were found when compared with those without ADHD. ${ }^{15}$ This suggests many children and young people being diagnosed with moderate-to-servere ADHD will require ongoing treatment from $\mathrm{ADHD}$ services and into adulthood.

In the UK, guidance into ADHD: diagnosis and management ${ }^{4}$ highlighted that in cases of persistent behavioural and/or attention problems with moderateto-severe impairment, the child or young person should be referred to a specialist ADHD provision (eg, CAMHS) for assessment by a specialist psychiatrist, paediatrician or other appropriately qualified healthcare professional with training and expertise in the diagnosis of ADHD.

An ADHD assessment includes a full clinical and psychosocial assessment of the person including a full developmental and psychiatric history; observer reports and assessment of the person's mental state. ${ }^{4}$ The guidelines stipulate that additional observations (eg, at school) are useful when there is doubt about symptoms. To make a diagnosis of ADHD, children and young people should be presenting with symptoms that meet the diagnostic criteria in DSM-5 ${ }^{12}$ or ICD- $10^{13}$ (hyperkinetic disorder); cause at least moderate psychological, social and/or educational or occupational impairment and be pervasive, occurring in two or more important settings including social, familial, educational and/or occupational settings. Early identification is important to improve outcomes for a child's educational and social development.

Nationally, CAMHS have been criticised for long waiting times. The Care Quality Commission ${ }^{16}$ highlighted children and young people waiting 18 months for 
treatment in some cases and long delays between assessment and treatment were common. A recent report by Young Minds ${ }^{17}$ found that in $2017-18$ only $30 \%$ of children and young people were seen for an initial assessment within 4 weeks with 4309 children waiting 18 weeks for an initial assessment with many waiting over 1 year. Half the 11482 children needing treatment waited $>18$ weeks following an initial assessment. Only $14 \%$ began treatment within 4 weeks following initial assessment in CAMHS. Mental health services have historically not had clear guidance on waiting time expectations and with increasing demands nationwide and limited capacity and resource, waiting times to access CAMHS assessment and treatment have increased. The recent government consultation, Transforming Children and Young People's Mental Health Provision: A Green Paper ${ }^{2}$ recommends a new standard on waiting times to access CAMHS to be within 4 weeks. This QI project aimed to manage demand and capacity issues within the ADHD pathway by streamlining processes, reducing variation and increasing the capacity for treatment.

\section{MEASUREMENT}

Through process mapping, which is used to develop a 'map' of a process within a system and can be used to identify areas for improvement, ${ }^{18-20}$ we established the key sections and processes of the pathway and began to collect demand and capacity data around them to build an understanding of the flow through the system. This included reviewing referral and discharge data, waiting times and how much clinical capacity was required for particular tasks. We identified bottlenecks, and explored variation relating to did not attend (DNA) appointments and cancellations.

We were able to build a model of the pathway, which allowed us to analyse how resources were used to meet demand, and where there might be inefficiency that could be reduced (figure 1).

Through reviewing the data and analysis, and conversation with staff and service users, the following aim statement was agreed:

To reduce the average length of time from initial referral to CAMHS to 'ADHD assessment feedback' to 12 weeks by September 2018 .

Data collection began in August 2017, with further baseline data being available for collection via existing clinical systems. The outcome measure was the time taken in weeks from referral to CAMHS to the completion of the ADHD assessment. Wait time between processes were collected on a spreadsheet to help further identify flow problems. Additional data collected specific to change

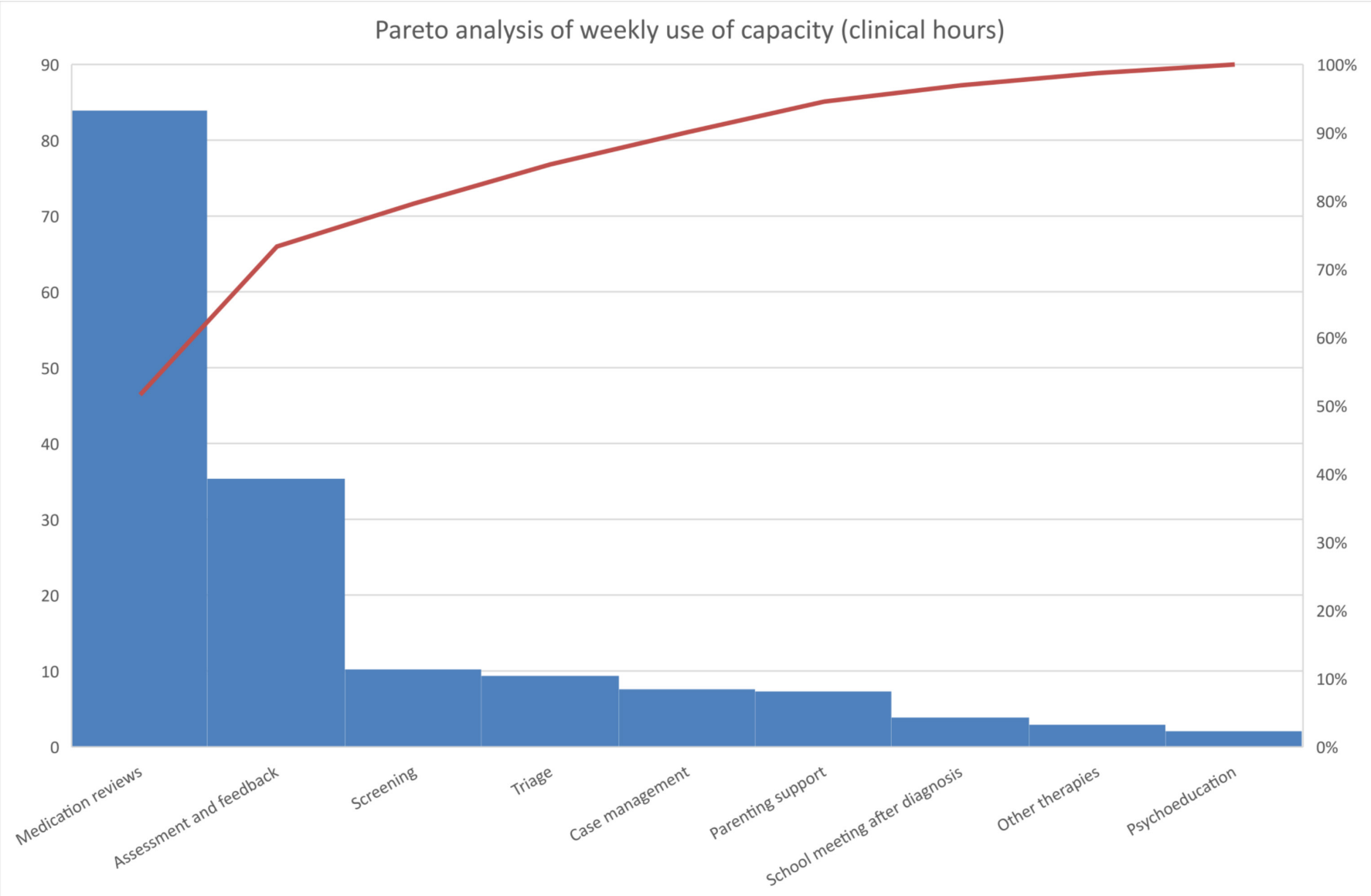

Figure 1 Pareto analysis of capacity use within the attention deficit hyperactivity disorder team (hours). 
Table 1 Model for improvement; measurement

\begin{tabular}{|c|c|c|}
\hline Measure type & Measure & Rationale \\
\hline Outcome & $\begin{array}{l}\text { 1. Time taken in weeks from referral to CAMHS to the } \\
\text { completion of an ADHD assessment. }\end{array}$ & 1. Derived from aim statement. \\
\hline
\end{tabular}

ADHD, attention deficit hyperactivity disorder; DNA, did not attend.

ideas and a number of process and balancing measures were also identified (table 1 ).

\section{DESIGN}

The QI project was led by the Principal Clinical Psychologist in the team. All members of the ADHD pathway were included as part of a QI project team. A QI Improvement Advisor from ELFT QI team attended regular meetings, supporting the lead and the team in moving forward with improvement techniques.

Regular fortnightly QI meetings were held as part of the multidisciplinary team meeting. This consisted of $30 \mathrm{~min}$ to 1 hour. Embedding QI into the multidisciplinary team meeting as part of the agenda meant that the whole team were present and were able to contribute to discussing progress, identifying change ideas and planning Plan-DoStudy-Acts (PDSAs).

Service users were consulted at the beginning of the QI project to identify key themes to get their views and experience of the assessment process. At the time, this was to help the team identify what service users felt were areas for improvement. Service users identified that the time it took to complete the assessment was long; they did not feel there was much intervention on offer postassessment and wanted more targeted support. This consultation with service users was done over the period of 1 month in September 2017. Patients attending the ADHD pathway were given the experience of service questionnaire ${ }^{21}$ and asked to provide feedback on the service they had received and any recommendations for improvements. Qualitative information was collated by the Assistant Psychologist and presented to the QI team to review. While this was helpful information at the time, we do not have a breakdown of the number of service users asked and further information on the comments made.

Based on service user feedback, the project used the model for Improvement ${ }^{18}{ }^{19}$ as a framework to work towards reducing waiting times in the ADHD pathway. Information regarding the model which the team followed can be found on the East London NHS Foundation Trust Microsite. ${ }^{20}$

\section{STRATEGY}

Our aim was to reduce the average length of time from initial referral to CAMHS to 'ADHD assessment feedback' to 12 weeks by September 2018, which is in line with trustlevel targets.

As a team, we developed our strategy using Nominal Group Technique and Affinity Diagram, where team members were asked to identify possible change ideas that might result in improvement. Primary and secondary drivers were identified and a driver diagram was developed (figure 2). The driver diagram was the strategy for the project and includes a list of all the change ideas. Ideas that were tested using PDSA cycles are highlighted on the driver diagram.

PDSA cycles were applied and evaluated in the QI framework to assess the impact of the following change ideas. Several PDSA cycles had a significant reduction on waiting times.

Prior to the QI project, the ADHD assessments were completed by two clinicians to form a multidisciplinary assessment in a set clinic. We planned to move to a model of one clinician care coordinating the case. When the clinician required another specific assessment (eg, cognitive assessments), this was arranged. Most clinicians continued using the same set afternoon, so there was some regularity in the availability of appointments and the move to one clinician improved the overall flow through the system.

A 'screening pack' was designed to include a standardised screening tool for ADHD (SNAP IV) for parents and school to complete. The plan was to send this out to families at referral to CAMHS with their first appointment letter. Screening packs were printed on coloured paper for recording purposes. This was first implemented in January 2018. However in the initial stages, it became apparent that the change idea had not been 


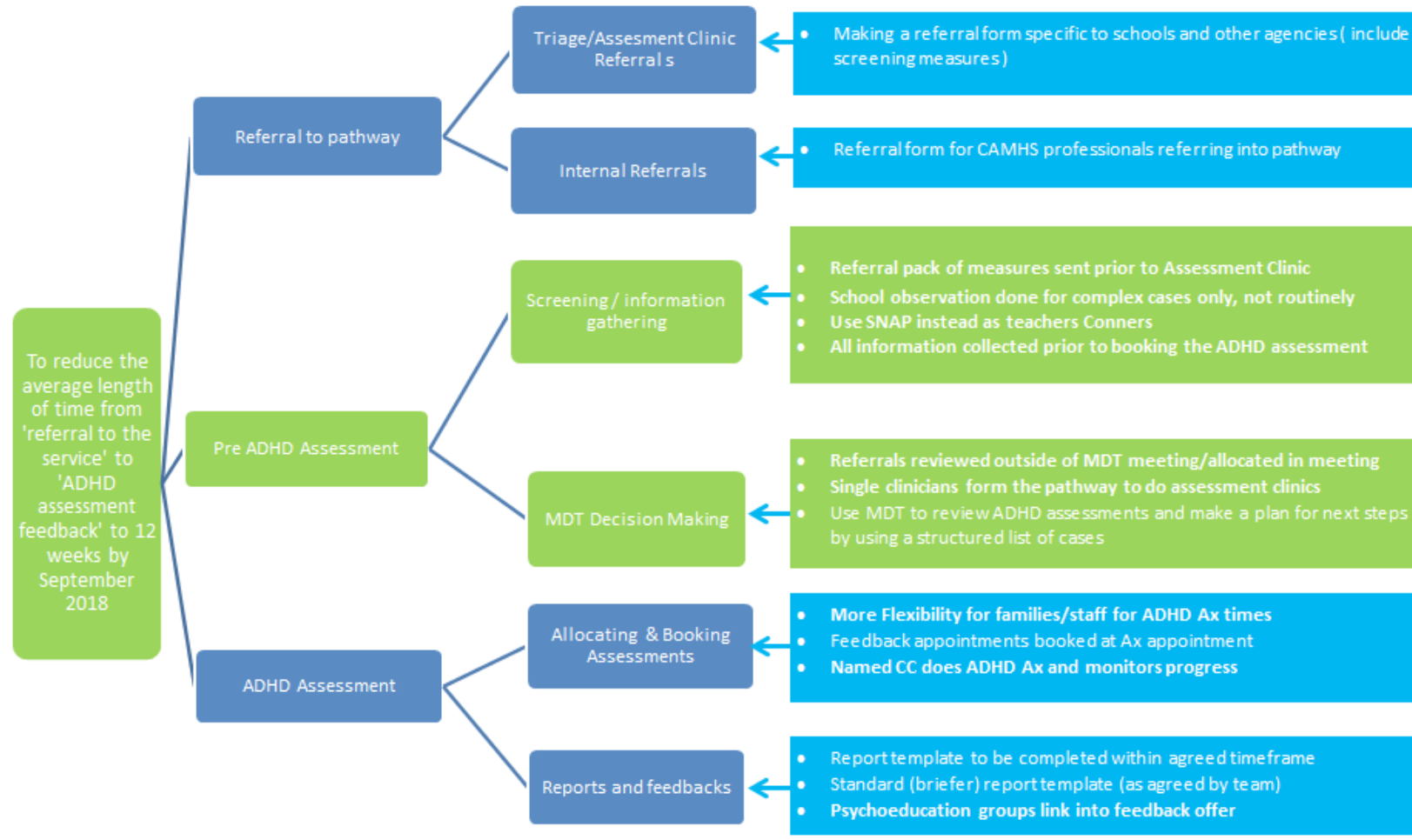

Figure 2 Driver diagram for the attention deficit hyperactivity disorder (ADHD) demand and capacity project. MDT, multidisciplinary team; SNAP, SNAP-IV.

embedded in the wider system and the Clinical Support Team (CST) were unsure what the process was when the forms returned. A process/flow chart was developed and a meeting with CST was held to support the process.

Over an 8-week period of data collection, $63 \%$ returned the questionnaires before the first appointment. Seventeen per cent did not return the forms but attended the first appointment. Twenty per cent appointments were classified as DNA. Following this result, CST staff started telephoning families who had not returned the screening pack prior to the first appointment which further increased the number being returned and reduced DNA rates.

The development and introduction of a new monitoring system into the ADHD pathway has helped the team to keep track of progress and highlight potential breeches. The system incorporates our referrals database and is reviewed weekly in the team meeting. It highlights cases approaching the 12-week target which has enabled cases to be prioritised and reviewed by the multidisciplinary team and to support the clinician to identify next steps and/or reasons for delay.

\section{RESULTS}

\section{Outcome measure}

There was an improvement as evidenced by a shift in the waiting time data (see further information about control chart rules). ${ }^{19}$ A reduction in the average wait from referral to CAMHS to the completion of an ADHD assessment was noted. However, data were skewed by referrals that were seen in other pathways of CAMHS before the need for ADHD assessment was identified (sometimes this added years to the measure). Therefore, despite a reduction in days waited, the average number of days waited remained higher than the team's target (figure 3). The process measure, time from referral to pathway to completion of ADHD assessment is a more accurate indication of improvement.

\section{Process measures}

The time taken from the referral to pathway to the completion and feedback of an ADHD assessment reduced from an average of 87 days to an average of 18 days (figure 4).

We saw improvement as evidenced by a shift in data when the team began testing their new screening process. The second shift in data occurred when the team began testing a new management process, identifying longer waiters.

For information about the measure of screening questionnaires returned from families and schools, see PDSA Design section detailing PDSA cycles.

\section{Balancing measures}

The proportion of assessments resulting in diagnosis increased. Data from 2017 (87 assessments completed; 


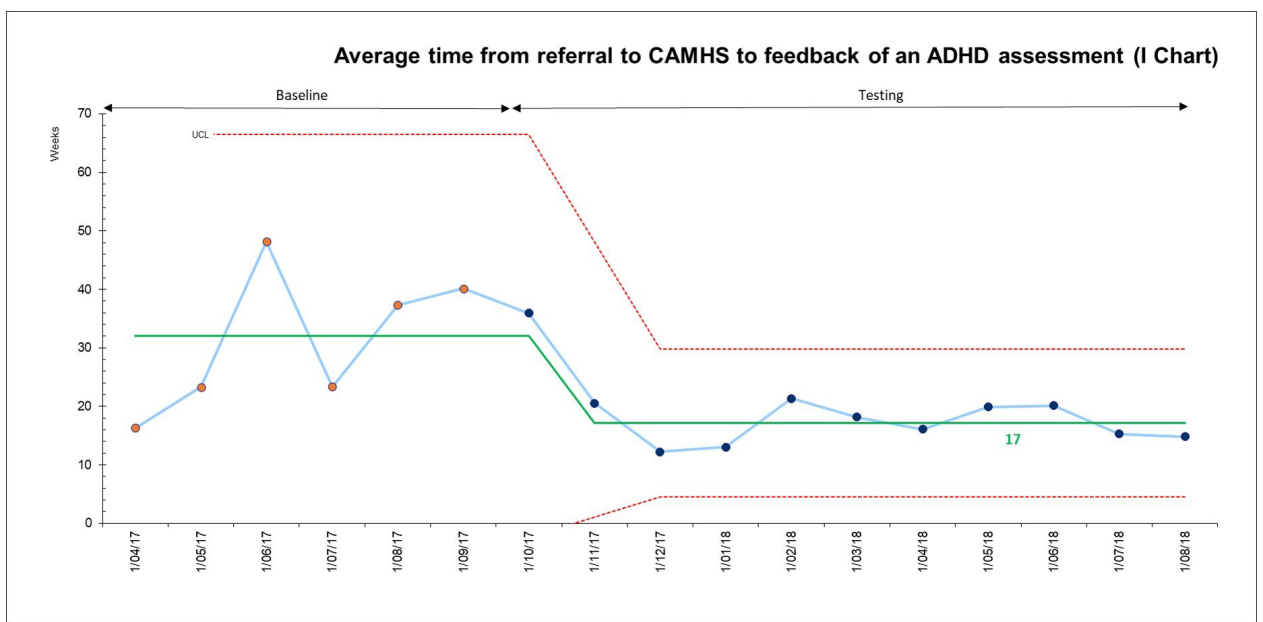

Figure 3 I chart to show average time in days between 'referral to CAMHS' and feedback of attention deficit hyperactivity disorder (ADHD) assessment.

50 diagnosed with $\mathrm{ADHD})$ revealed a diagnostic rate of $62 \%$. This was compared with data collected following the onset of change ideas (January 2018-June 2018; 53 assessments were completed and 41 diagnosed with ADHD) resulting in an diagnostic rate of $78 \%$.

The proportion of appointments classified as DNA or cancelled was measured as DNA's cause wasted capacity within the service (figures 5 and 6 , respectively). A reduction in DNA rate was seen following the implementation of new letter which stipulated the importance of attendance. Summer holidays coincided with an increase in DNA rate.

There is a similar peak in cancellations during the school summer holidays. However, overall the number of cancellations remain stable at $10 \%$.

\section{Referral and discharge numbers}

The pathway saw an increase in referrals following the introduction of new screening processes (figure 7). An increase in discharges is also observed (figure 8).

\section{Qualitative feedback}

Parents and young people complete a Evaluation of Service Questionnaire. ${ }^{21}$ Ongoing feedback from those who have been through the ADHD assessment process often report they were happy with the speed their child was seen and the quality of the assessment and support they received.

\section{DISCUSSION}

Overall, using QI methodology has enabled the ADHD team to reduce their waiting times for children and young people being referred for an ADHD assessment. As with any change, there were concerns about the increase in workload completing a QI project would have on an overstretched team. The team initially resisted the idea with concerns regarding an increase in workload and the need for more resources to change the system. However, working together on a shared aim has increased motivation and team ownership. Embedding QI into the team as part of the regular agenda gave everyone an opportunity to participate. The team approach was an important factor in making this project successful.

The primary outcome measure or aim of the study to ensure children and young people referred to CAMHS for an ADHD assessment was seen within 12 weeks was heavily skewed by referrals that were seen in other pathways of CAMHS before the need for an ADHD assessment was identified (sometimes this added years to the

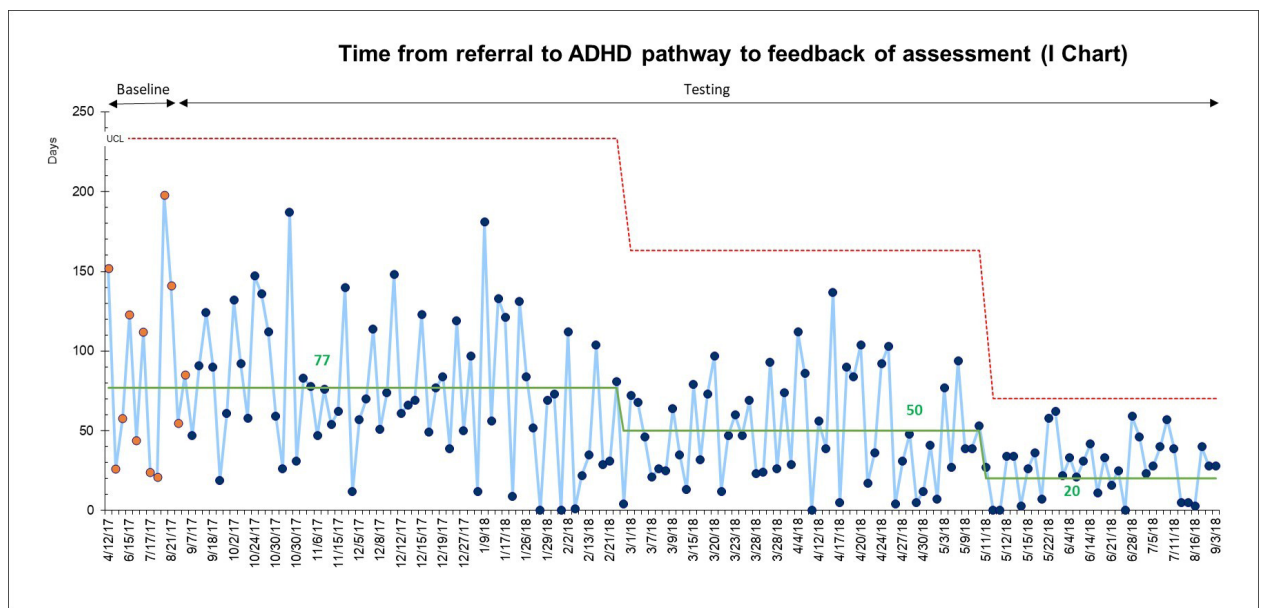

Figure 4 I chart to show referral to attention deficit hyperactivity disorder (ADHD) pathway to completion and feedback of ADHD assessment. 


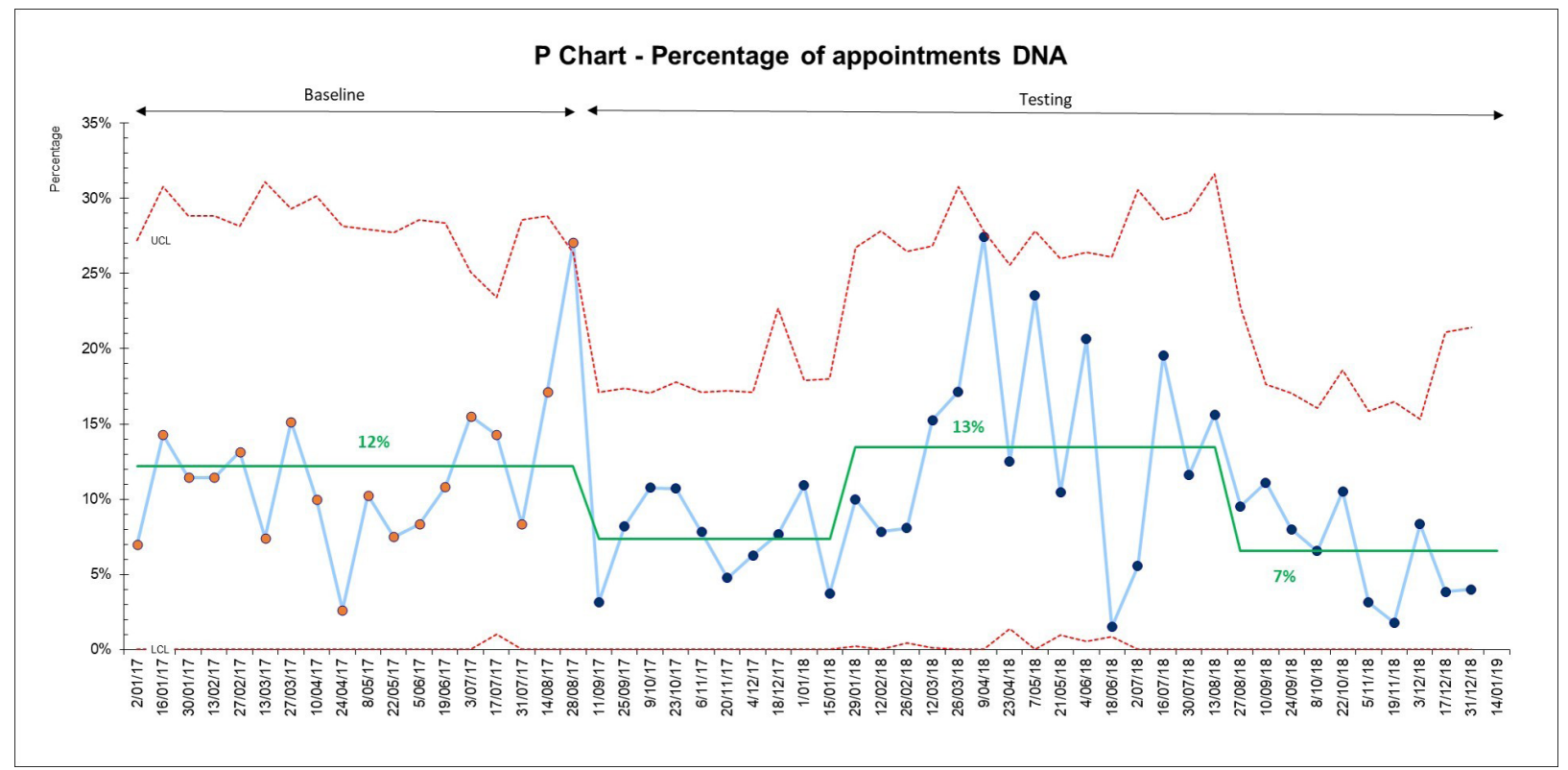

Figure $5 \mathrm{P}$ chart to show the percentage of appointments recorded as did not attend (DNA).

measure). However, days from referral to the ADHD pathway to the completion of the ADHD assessment did demonstrate a significant reduction in waiting times.

Balancing measures revealed an increase in diagnostic rate. This could be for a number of reasons. The quality of the routine use of standardised screening measures and improved quality of information collated by clinicians means a more thorough assessment was being completed and a diagnostic decision could be confidently made. It is also likely that the referrals coming through to the pathway were more appropriate due to the screening measures being received prior to referral to the pathway. The new screening process may also account for the increase in referrals, where it is likely that this additional screening meant more children and young people than usual were identified as possibly having ADHD.

An increase in discharges has had an impact on the team's capacity and flow in the system. A clearer assessment process and postdiagnostic offer means more families get discharged following the assessment, postdiagnostic parenting group and recommendations for schools to support the child with their new diagnosis. Only those requiring additional mental health treatment for co-existing conditions and/or who require medication to manage their ADHD will remain open to the service.

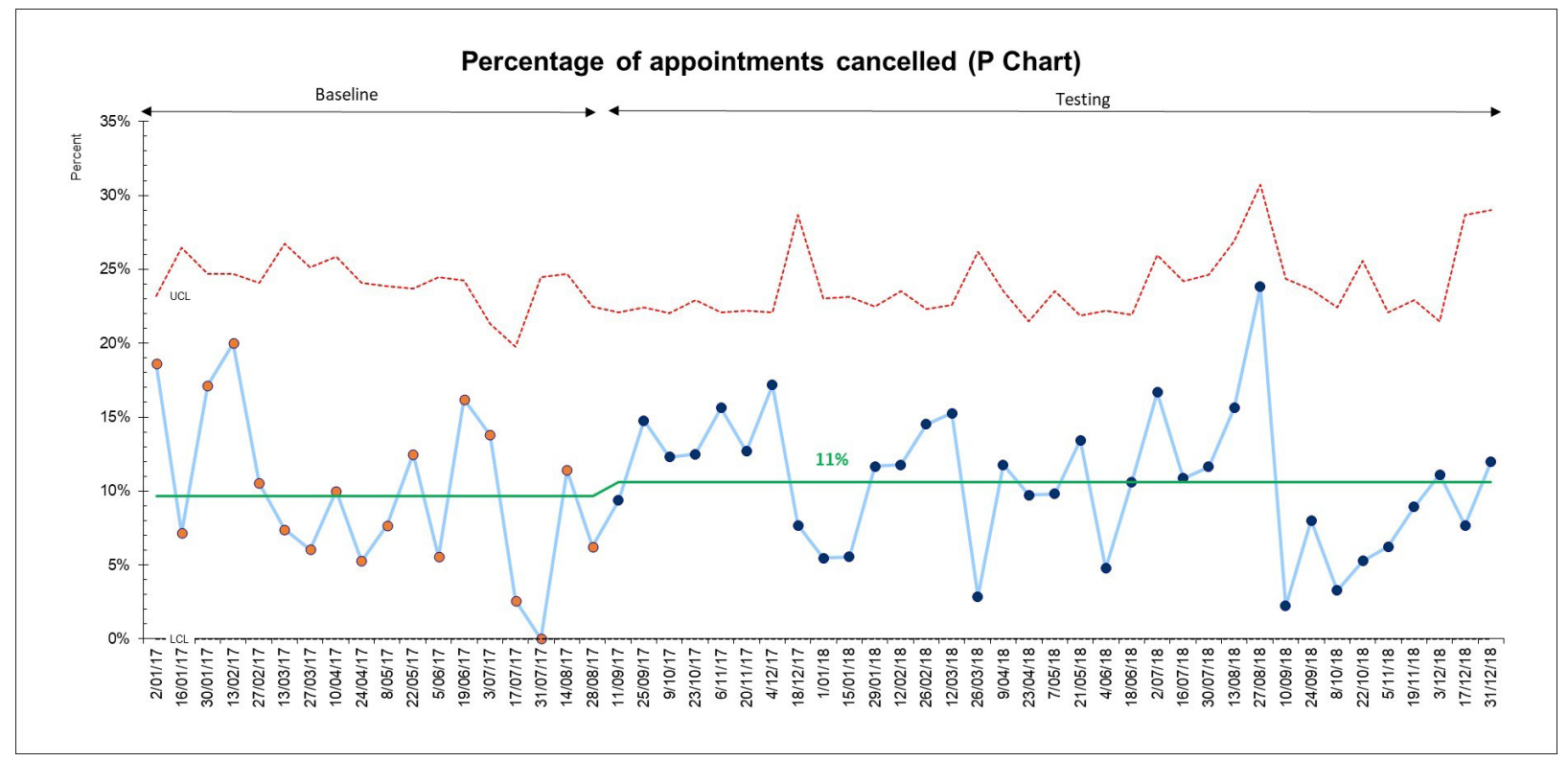

Figure $6 \mathrm{P}$ chart to show the percentage of appointments cancelled by service user. 


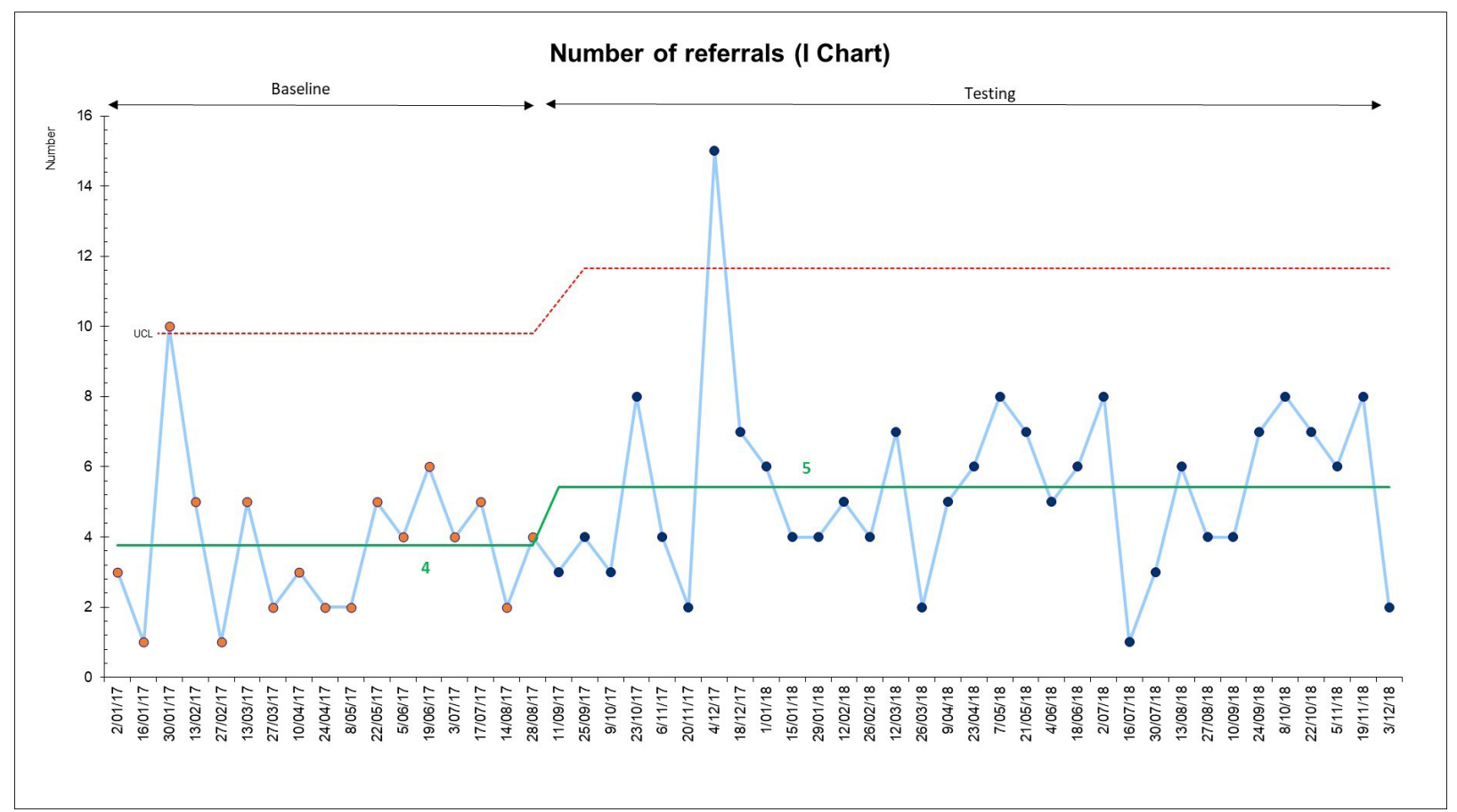

Figure 7 I chart to show the number of referrals received.

\section{LESSONS AND LIMITATIONS}

QI is designed to be used by NHS staff working within local systems. It is important to acknowledge that the QI team in this project were heavily invested in the project bringing about change. For this reason, there is potentially a bias on the interpretation of the findings.

Due to the nature of a QI project, this project developed and evolved over time and in hindsight there were a number of important changes that were not captured in the data but would have been interesting to have further explored. The impact on the team is one of those. Through conversations with colleagues and experiences within regular team meetings there appears to be a positive difference in team morale, motivation and enjoyment. It would have been useful to measure this over time. As a team, we learnt about embedding change in the wider system. The initial PDSA cycles were implemented hastily and resulted in some confusion with our CST as the process had not been considered wider than the impact on the ADHD team. The team learnt from this and once a change idea was agreed, a plan for implementation was established to take into account other systems

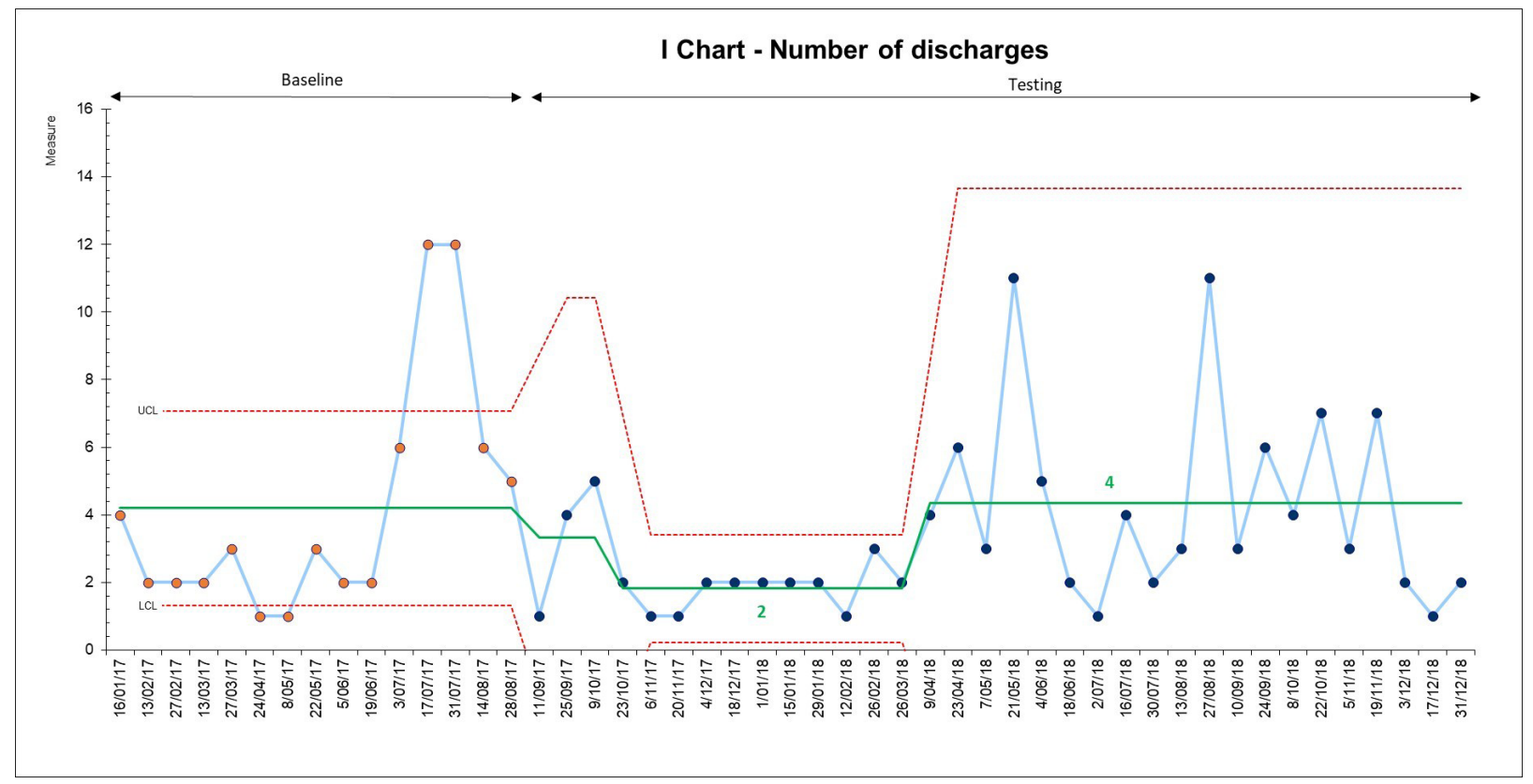

Figure 8 I chart to show the number of discharges from the service. 
which would need to know about the process. The wider team were inquisitive and adaptable, enabling changes to be implemented.

Our new monitoring system adds transparency to workload and has provided a system to view pathway more objectively and use data to identity and monitor bottlenecks in the system. This in itself has identified areas for development within the workforce while also highlighting strengths within the team and pathway. It is hoped that this system will enable us to identify changes in wait times and to modify processes to reduce waits accordingly.

A novel aspect of this QI project is the top down nature of the CAMHS wide demand and capacity work in ELFT. The QI projects were agreed at a director and senior management level within the trust. There was an executive sponsor who was involved in receiving regular updates on a series of demand and capacity projects across the four ELFT CAMHS teams. A learning system was set up for project leads to meet and discuss progress and a QI Improvement Advisor regularly joined project meetings. The QI project was not completed in isolation within a single service, but as part of a large network within which challenges and learning has been shared. Other services may benefit from this approach, particularly when trying to embed QI into a system.

\section{CONCLUSIONS}

Transformation plans for children and young people's mental health provision ${ }^{1-3}$ focus on early identification, increasing access to services and reducing waiting times for children and young people. To date, there has not been clear guidance on waiting time expectation within CAMHS. However, with increasing demands and limited capacity and resource nationwide, waiting times to access CAMHS remain a concern.

The Model for Change ${ }^{18-20}$ has provided a framework for implementing positive change within the ADHD pathway. The aim to reduce wait times has been met. The team is currently in the quality control phase and developing strategies to review, reflect and respond to current data.

Overall, there has been a reduced demand on clinician's time in completing ADHD assessments (eg, reduction in the work per a referral). The screening pack has enabled clinicians to make a decision at referral to the pathway around what steps are most likely required in the assessment and what clinical discipline it is best suited too.

The improvement to waiting times and changes to the assessment process has increased capacity. Clinicians have been able to develop and deliver regular parenting groups which have been received with positive feedback from families. This is more in line with NICE guidelines for $\mathrm{ADHD},{ }^{4}$ which suggest postdiagnostic psychoeducation; specialist parenting and support for the young person in developing skills to manage their ADHD symptoms. The team are currently developing a postdiagnosis package of care for young people and families.

While the data reflect improvements in waiting times, it is also important to reflect on the improved experiences of working in the team. Processes are smoother, team members work together and there is a sense of increased motivation and team ownership.

The QI methodology has been a helpful approach to improving demand and capacity within the ADHD pathway.

Acknowledgements The authors would like to thank individual team members from the City and Hackney ADHD team for their dedication and hard work and the service users for their feedback throughout the project. Dr Mosun Dorgu, Child and Adolescent Psychiatrist, Dr Jenny Parker, Child and Adolescent Psychiatrist, Jessica Brunet Cooke, Specialist Nurse and Nurse prescriber, Dr Julie Proctor, Consultant Clinical Psychologist, Dr Lisa Walker, Clinical Psychologist, Alison Wilson, Specialist Nurse, Esther Donkor, Family Therapist, Ellen 0'Gorman, Assistant Psychologist, Louise Mercer, Assistant Psychologist, Hawa Moola, Clinical Support Team, Maha Amin, Clinical Support Team.

Contributors The quality improvement (QI) project was planned and executed by LAR, Clinical Psychologist in conjunction with colleagues in the CAMHS City and Hackney ADHD team. The team received support from Improvement Advisor, JS from the QI team in ELFT. The findings were written up by LAR and JS. The ADHD team and wider CAMHS team supported the project and played a role in collecting data, implementing change ideas and making it happen. LAR is responsible for the accuracy of the overall content.

Funding The authors have not declared a specific grant for this research from any funding agency in the public, commercial or not-for-profit sectors.

Competing interests None declared.

Patient consent for publication Not required.

Provenance and peer review Not commissioned; externally peer reviewed.

Open access This is an open access article distributed in accordance with the Creative Commons Attribution Non Commercial (CC BY-NC 4.0) license, which permits others to distribute, remix, adapt, build upon this work non-commercially, and license their derivative works on different terms, provided the original work is properly cited, appropriate credit is given, any changes made indicated, and the use is non-commercial. See: http://creativecommons.org/licenses/by-nc/4.0/.

\section{REFERENCES}

1 NHS England. Implementation plan for five year forward view for mental health, 2016. Available: https://www.england.nhs.uk/ mentalhealth/wp-content/uploads/sites/29/2016/07/2.-Children-andyoung-people's-mental-health.pdf [Accessed 21 Dec 2018].

2 Department of Health and Social Care and the Department for Education. Transforming children and young people's mental health provision; a green paper, 2018.

3 The Children's Comissioner. Children's Mental health Briefing.. Available: https://www.childrenscommissioner.gov.uk/wp-content/ uploads/2019/02/childrens-mental-health-briefing-nov-2018.pdf [Accessed 14 Aug 2019].

4 NICE. Attention deficit hyperactivity disorder: diagnosis and management. NICE guideline (NG87), 2018. Available: https://www. nice.org.uk/guidance/ng87 [Accessed 21 Dec 2018].

5 NHS England. Delivering effective services for children and young people with ADHD. good practice guidance for commissioners and service providers across greater Manchester, 2018. Available: https:// www.england.nhs.uk/north-west/wp-content/uploads/sites/48/2019/ 03/GM-wide-ADHD-guidance.pdf [Accessed 14 Aug 2019].

6 Zekria D, Shah A, Malik Y, et al. Improving access to City and Hackney adult mental health services. BMJ Open Qual 2017;6.

7 City and Hackney Health and wellbeing profile. Joint strategic needs assessment data update, 2014. Available: https://www.cityoflondon. gov.uk/services/health-and-wellbeing/Documents/city-and-hackneywellbeing-profile.pdf [Accessed 21 Dec 2018].

8 Woodard R. The diagnosis and medical treatment of ADHD in children and adolescents in primary care: a practical guide. Pediatr Nurs 2006;32:363-70. 
9 Conners CK. Connors 3rd edition (Conners 3). Pearson assessment, 2008.

10 NHS England. Demand and capacity programme. Available: https:// www.england.nhs.uk/ourwork/demand-and-capacity/about/ [Accessed 15 Aug 2019].

11 American Psychiatric Association. Diagnostic and statistical manual of mental disorders. 4th edn. Washington, DC: American Psychiatric Association, 1994.

12 American Psychiatric Association. Diagnostic and statistical manual of mental disorders. 5th edn. Washington, DC: American Psychiatric Association, 2013.

13 World Health Organization. The ICD-10 classification of mental and behavioural disorders 1: 1-263, 1993. Available: www.who.int/entity/ classifications/icd/en/bluebook.pdf [Accessed 21 Dec 2018].

14 Owens E. Developmental Progression and Gender Differences among Individuals with ADHD. In: Barkley RA, ed. Attention-Deficit hyperactivity disorder: a Handbook for diagnosis and treatment. 4th edn. New York, NY: Guilford Press, 2015: 223-55.

15 Biederman J, Petty CR, Woodworth KY, et al. Adult outcome of attention-deficit/hyperactivity disorder: a controlled 16-year follow-up study. J Clin Psychiatry 2012;73:941-50.
16 Care Quality Commission. Brief guide: waiting times for community child and adolescent mental health services, 2017. Available: https:// www.cqc.org.uk/sites/default/files/20180228_briefguide-camhs_ waitingtimes_v2.pdf [Accessed 21 Dec 2018].

17 Young Minds. A new era for young people's mental health, 2018. Available: https://youngminds.org.uk/media/2620/a-new-era-foryoung-peoples-mental-health.pdf [Accessed 21 Dec 2018].

18 Institute for Healthcare Improvement. Quality improvement essentials toolkit. Boston: Institute for Healthcare Improvement, 2019.

19 Langley GL, Ronald DM, Nolan KM, et al. The improvement guide: a practical approach to enhancing organizational performance. 2nd edn, 2009.

20 East London NHS Foundation Trust Quality Improvement Microsite. The model for improvement, 2019. Available: https://qi.elft.nhs.uk/ resource/the-model-for-improvement/ [Accessed 14 Aug 2019].

21 Experience of Service Questionnaire. Commission for Health Improvement (CHI). Development of methods to capture users' views of CAMHS in clinical governance. A project evaluation report, 2017. Available: https://www.corc.uk.net/outcome-experiencemeasures/experience-of-service-questionnaire/ [Accessed 14 Aug 2019]. 